\title{
Quality of Participation Experiences in Special Olympics Sports Programs
}

Kelly P. Arbour-Nicitopoulos, Natasha Bruno, Krystn Orr, Roxy O’Rourke, Virginia Wright, Rebecca Renwick, Kirsten Bobbie, James Noronha

Version Post-print

Citation Arbour-Nicitopoulos, K. P., Bruno, N., Orr, K., O’Rourke, R., Wright, V., (published version) Renwick, R., Bobbie, K., \& Noronha, J. (2021). Quality of Participation Experiences in Special Olympics Sports Programs, Adapted Physical Activity Quarterly (published online ahead of print 2021). Retrieved from https://journals.humankinetics.com/view/journals/apaq/aop/article10.1123-apaq.2021-0033/article-10.1123-apaq.2021-0033.xml

Copyright / C Human Kinetics, Inc.

License

Publisher's Accepted author manuscript version reprinted, by permission, from

Statement Adapted Physical Quarterly, 2021, https://doi.org/10.1123/apaq.20210033. (C) Human Kinetics, Inc.

\section{How to cite TSpace items}

Always cite the published version, so the author(s) will receive recognition through services that track citation counts, e.g. Scopus. If you need to cite the page number of the author manuscript from TSpace because you cannot access the published version, then cite the TSpace version in addition to the published version using the permanent URI (handle) found on the record page.

This article was made openly accessible by $U$ of $T$ Faculty. Please tell us how this access benefits you. Your story matters. 


\section{Quality of Participation Experiences in Special Olympics Sports Programs}

2 Kelly P. Arbour-Nicitopoulos, ${ }^{1}$ Natasha Bruno, ${ }^{2}$ Krystn Orr, ${ }^{1}$ Roxy O’Rourke, ${ }^{1}$ Virginia

3 Wright, ${ }^{3,4}$ Rebecca Renwick, ${ }^{5}$ Kirsten Bobbie, ${ }^{6}$ James Noronha ${ }^{6}$

4

$5 \quad{ }^{1}$ Faculty of Kinesiology and Physical Education, Mental Health and Physical Activity Research

6 Centre, University of Toronto, Toronto, Ontario, Canada

$7 \quad{ }^{2}$ School of Kinesiology and Health Studies, Queen's University, Kingston, Ontario, Canada

$8 \quad{ }^{3}$ Department of Physical Therapy, University of Toronto, Toronto, Ontario, Canada

$9{ }^{4}$ Bloorview Research Institute, Holland Bloorview Kids Rehabilitation Hospital, Toronto,

10 Ontario, Canada

$11{ }^{5}$ Department of Occupational Science and Occupational Therapy, University of Toronto,

12 Toronto, Ontario, Canada

$13 \quad{ }^{6}$ Special Olympics Ontario, Toronto, Ontario, Canada

15 Corresponding Author: Kelly Arbour-Nicitopoulos, Faculty of Kinesiology and Physical

16 Education, 55 Harbord Street, University of Toronto, Toronto, Ontario, M5S 2W6. Phone: 416-

17 978-2725. Email: kelly.arbour@utoronto.ca

19 Acknowledgements: This study was made possible through the support and funding from

20 Special Olympics Canada. The authors would like to acknowledge the contribution of all Special

21 Olympics youth athletes who participated in this study.

Disclosure: The authors declare no conflict of interest. 


\section{Abstract}

2 This cross-sectional study examined experiential elements facilitating quality sport experiences

3 for youth (ages 12-24) in Special Olympics, and the associated influences of sport program and

4 sociodemographic characteristics. A total of 451 athletes involved in the 2019 Special Olympics

5 Youth Games completed a survey assessing elements of quality participation (autonomy,

6 belongingness, challenge, engagement, mastery, meaning). T-tests investigated whether athletes

7 with intellectual and developmental disabilities (IDD) rated elements differently across

8 Traditional and Unified Sport. Regression analyses explored whether sport program and

9 sociodemographic characteristics were predictors of these elements. Youth reported high mean

10 scores across the elements, with no significant differences between athletes with IDD in

11 Traditional or Unified Sport. Athletes with no reported disability rated higher autonomy than

12 those who reported disability $(p=.01)$. Women tended to report greater engagement in sport than

13 men $(p=.07)$. Findings provide theoretical and practical insights into youth's quality sport

14 participation in Special Olympics.

16 Keywords: youth; intellectual disability; developmental disability; Unified Sport; integration 


\section{Introduction}

Participation in sport can offer important health benefits for youth of all abilities

including improved physical fitness (Montesano et al., 2014; Oliveira et al., 2017), psychological well-being (Crawford et al., 2015; Eime et al., 2013), and social functioning (Eime et al., 2013; Reinders et al., 2019; Wilson et al., 2016). Unfortunately, youth with disabilities encounter multiple physical, program, and social barriers that have impeded both the quantity and quality of their sport participation (Evans et al., 2018; McGarty \& Melville, 2018). In particular, youth with intellectual and developmental disabilities (IDD) who have impairments in intellectual functioning and adaptive behaviour (American Association on Intellectual and Developmental Disabilities, 2020) experience barriers to sport access and participation, including a lack of accessible facilities, limited availability of inclusive programs, insufficiently trained instructors, and negative attitudes and stereotypes of persons with disabilities (McGarty \& Melville, 2018). Accordingly, sport programs should be equipped to support the participation of youth, especially those with IDD who experience greater obstacles and exhibit lower levels of sport participation compared to youth without IDD (Shields \& Synnot, 2016).

Special Olympics offers community-based health and wellness opportunities, including sport programs, to over five million persons with IDD internationally and 45,000 in Canada (Robinson et al., 2018; Weiss et al., 2017). Initially, Special Olympics offered sports programming for individual- and team-based 'Traditional Sports', which are segregated sports programs for athletes with IDD to train and compete against other athletes with IDD. Recognizing their mission to promote sport that both empowers athletes with IDD and inspires understanding within local communities, Special Olympics established Unified Sport. These are integrated sports programs that offer the opportunity for athletes with and without IDD to 
1 participate in sports on the same team, with the aim of fostering social inclusion through shared

2 sport experiences (Hassan et al., 2012). Given the widespread global support for Special

3 Olympics, and the well-known physical, psychological, and social benefits of Special Olympics

4 sport participation (Orr et al., 2019; Shapiro, 2003; Tint et al., 2017), it is expected that exploring

5 experiences of youth in Special Olympics' Traditional and Unified Sport programs can offer

6 insights into the quality of participation among youth with and without IDD in sport.

$7 \quad$ Broadened understandings of quality sport participation for persons with disabilities has

8 evolved into a growing body of research. In 2017, Martin Ginis et al. conducted a configurative

9 review (Gough et al., 2012) to synthesize the literature on 'quality participation' for children,

10 youth, and adults with physical disabilities across all life domains (e.g., leisure, employment,

11 education). Based on their findings, quality participation was defined as a person's subjective

12 evaluation that their participation is satisfying and enjoyable, and leads to personally valued

13 outcomes. Martin Ginis et al. (2017) posited six experiential elements fostering quality

14 participation: autonomy (e.g., making choices for oneself), belongingness (e.g., feeling accepted

15 by others), challenge (e.g., perceiving tasks to be stimulating), engagement (e.g., involving

16 oneself in the tasks), mastery (e.g., task accomplishments), and meaning (e.g., perceiving a sense

17 of purpose and social responsibility). Martin Ginis et al. (2017) recommended that researchers,

18 clinicians, and policymakers incorporate these six experiential elements into the design and

19 implementation of community participation initiatives for persons with physical disabilities.

20 Building upon Martin Ginis et al.’s (2017) conceptualization of quality participation,

21 Evans et al. (2018) developed a sport-specific framework that incorporates the six experiential

22 elements with evidence-informed strategies for supporting the physical, program, and social

23 environments within parasport. Within this framework, Evans et al. (2018) stipulated that 
1 repeated exposure to the six experiential elements can promote quality experiences, and,

2 consequently, quality participation in sport environments. Several studies examining quality

3 sport and physical activity participation of parasport athletes (Allan et al., 2018), recreational

4 sport athletes with physical disabilities and IDD (Orr et al., 2019), and military veterans with

5 physical disabilities (Shirazipour et al., 2017) provided evidence for the six experiential elements

6 and their role in fostering quality sport experiences for athletes with disabilities.

7 Despite advancements in operationalizing quality sport participation, previous efforts

8 have largely focused on persons with physical disabilities. Investigations that explore quality

9 sport participation for persons with IDD would help ensure that theoretical, practical, and

10 methodological developments include all persons with disabilities. More specifically, analyzing

11 perceptions of Martin Ginis et al.'s (2017) experiential elements of quality participation in the

12 largest international sports organization dedicated to persons with IDD, Special Olympics, could

13 narrow the current research gap concerning quality sport participation for youth with IDD. Very

14 importantly, exploring quality sport participation among Special Olympics Traditional and

15 Unified Sport athletes offers the unique opportunity to examine whether differences in

16 experience emerge across youth with and without IDD. Such investigations could clarify whether

17 youth with IDD participating in Unified Sport rate the quality of their sport experience similar to

18 youth with IDD participating in Traditional Sports. Further, by consulting with athletes, Special

19 Olympics instructors may better understand how youth athletes with and without IDD rate their

20 experience and consequently, how to improve the quality of their sport programming.

21 To date, there has been limited research examining sport participation experiences of

22 Special Olympics athletes, and whether differences in experiences are related to sport program

23 (i.e., Traditional or Unified) or sociodemographic characteristics (e.g., age, disability status, 
1 gender). However, such investigations are necessary to better understand whether all athletes are

2 meaningfully included and adequately supported in sport environments to mitigate challenges in

3 participation. There is some evidence to suggest that parents of youth with IDD tend to select

4 segregated sports options over integrated programs (Goodwin et al., 2006). Recurring themes in

5 Goodwin et al.'s (2006) data suggested youth with IDD who participated in integrated sport

6 programs outside of Special Olympics perceived differences in skill level compared to youth

7 without IDD, leading to overly competitive sport environments and negative social comparisons.

8 Parents perceived integrated sports environments as lacking appropriately tailored modifications

9 for youth with IDD, threatening self-efficacy and producing discomfort and unsatisfactory

10 participation experiences (Goodwin et al., 2006).

11 Similarly, Ninot et al. (2005) and Ninot and Maïano (2007) found youth with IDD

12 participating in Special Olympics Traditional swimming programs reported significantly higher

13 self-perceptions of athletic competence compared to youth with IDD participating in non-Special

14 Olympics integrated swimming programs. As such, Ninot et al. (2005) stressed the importance of

15 having professionals monitor the integrated sport environment to ensure youth with IDD are

16 supported through ongoing encouragement and opportunities to maximize success. One

17 limitation with these studies is the lack of exploration of integrated sports within Special

18 Olympics (i.e., Unified Sport), suggesting the need to further investigate whether Special

19 Olympics' Unified Sport programming can elicit equally meaningful outcomes for youth athletes

20 with IDD compared to segregated (i.e., Traditional) sport programming. Additionally, these

21 studies did not recruit youth without IDD, and thus, the authors could not analyze whether these

22 outcomes differed across youth with and without IDD. 
In terms of the influence of sociodemographic characteristics on quality sport

2 participation, Gillespie (2009) examined patterns of age and gender among Special Olympics

3 athletes (i.e., children, youth, and adults) to explore whether the organization's aim of inclusivity

4 engaged all athletes. Results demonstrated significant sociodemographic gaps in participation,

5 highlighting that Special Olympics athletes were predominately male and older than 18 years

6 (mean age 32.6 years; standard deviation [SD] 15.3 years). Thus, to better understand how

7 Special Olympics can optimize participation for all athletes, it is important to consider the

8 quality of sport experiences for younger athletes and women/girls with IDD.

9 Accordingly, the overarching purpose of this study was to investigate the quality of

10 participation experiences of youth athletes in Special Olympics Traditional and Unified Sport

11 programs. By focusing on the experiences of youth with and without IDD, we hope to broaden

12 understandings of quality sport participation for youth of all abilities and further, delineate any

13 differences among these athletes across sport program and sociodemographic characteristics. Our

14 study focused on the self-reported experiences of Special Olympics youth athletes using the

15 experiential elements of quality participation as outlined in Martin Ginis et al.'s (2017)

16 framework. Three research questions guided this study:

17 1. How do youth athletes rate the quality of their participation in Special Olympics

$18 \quad$ Traditional and Unified Sport programming?

19 2. Do the sport participation experiences of Special Olympics athletes with IDD differ in

$20 \quad$ Traditional versus Unified Sport programming?

21 3. How do Special Olympics youth athletes' ratings of quality participation vary across

22 Traditional and Unified Sports programs, as well as within sociodemographic (e.g., age,

23 disability status, gender) characteristics? 


\section{Methods}

\section{Participants}

The study was conducted at the 2019 Special Olympics Invitational Youth Games where

4 approximately 1,260 international youth athletes competed as part of Traditional and/or Unified

5 Sport teams over a 3-day period in Toronto, Ontario, Canada. Institutional Review Board

6 approval was obtained along with Informed consent from participants prior to data collection.

7 Athletes were invited to participate in the Youth Games if they were deemed eligible based on

8 their performance in qualifying events held across Special Olympics Chapters or if they were

9 selected by Special Olympics Chapters to be on a representative team. Among the 1,260 Youth

10 Games athletes, the majority identified as man/boy $(n=828 ; 65.7 \%)$, were above the age of 17

$11(n=811 ; 64.4 \%)$, and reported on their registration form to have a disability $(n=1,056 ; 83.8 \%)$.

12 Of the 1,260 youth athletes who attended the Youth Games, 501 (40\%) participated in this study.

13 The inaugural invitational Youth Games presented a rich opportunity to explore whether

14 youth athletes' quality sport participation experiences differed based on the Sports program (i.e.,

15 Traditional versus Unified) and sociodemographic characteristics (i.e., age, disability status, and

16 gender) to try to elucidate the complexities of quality sport participation experiences for youth

17 with IDD. Eligible youth athletes with and without IDD were: (a) aged 12-24 years, (b)

18 competing in either Special Olympics' Traditional Sports or Unified Sport during the Youth

19 Games, (c) able to complete an online survey with minimal assistance from a researcher, and (d)

20 able to read or understand English. While the United Nations (2020) define youth as persons

21 aged 15-24 years, the eligibility criteria were expanded in this study to include athletes aged 12-

2224 as they were deemed to be youth by Special Olympics and thus took part in these Youth 
1 Games. As such, it was important to include the perspectives of athletes aged 12-24 years in our

2 statistical analyses to reflect how Special Olympics programming is carried out in practice.

\section{Measures}

4 Demographics

Athletes were asked to report their age, country of residence, disability status (i.e., "I

6 have a disability", "I do not have a disability", or "prefer not to answer"), gender (i.e., man/boy,

7 girl/woman, transgendered, or prefer not to answer), the sports they competed in (i.e., athletics,

8 basketball, bocce, floor hockey, and soccer), and sport program (i.e., Traditional Sport or Unified

9 Sport). A comment box was included for participants to add further details.

\section{Experiential Elements of Quality Participation}

11 Quality of participation experiences was assessed using the Measure of Experiential

12 Aspects of Participation (MeEAP) (Caron et al., 2018). The MeEAP is a 12-item questionnaire

13 designed to assess the six experiential elements of quality participation (i.e., autonomy,

14 belongingness, challenge, engagement, mastery, and meaning) that has been validated among

15 adults with physical disabilities across the domains of sport, exercise, employment, and mobility.

16 Each of the six experiential elements are represented by two items on the MeEAP, and presented

17 with the introductory statement in which the particular program name is inserted: "Think of your

18 [Special Olympics sports program]. When participating in [Special Olympics sports programs], I

19 feel...". Examples of the items include: "free to make my own choices" (autonomy), "accepted

20 by others" (belongingness), "my skills match the level of difficulty of the activity" (challenge),

21 “entirely focused on what I am doing” (engagement), "I can achieve my goals" (mastery), and "a

22 sense of purpose" (meaning). For this study, minimal modifications were made to the MeEAP, as

23 guided by co-authors Kirsten and James from Special Olympics Ontario, to appropriately tailor 
1 the language for youth athletes with IDD (see Supplemental Material for further details). MeEAP

2 responses are reported on a 7-point Likert scale (1 [strongly disagree] to 7 [strongly agree]).

3 Mean scores are calculated for each of the six experiential elements, with higher scores

4 representing more positive (i.e., higher quality) sport participation experiences.

\section{$5 \quad$ Study Design and Data Collection Procedures}

This descriptive study employed a cross-sectional design. Athletes involved in the 2019

7 Special Olympics Youth Games in Toronto, Ontario, Canada were invited to participate in a five-

8 minute online survey. The online survey was hosted on a secure institutional data management

9 system (RedCap ${ }^{\circledR}$; Harris et al., 2009). Using iPads, participants provided consent, completed

10 the demographics questions, and MeEAP measure. A team of 10 research assistants collected

11 data and assisted youth athletes in completing the online survey (i.e., by verbally reading aloud

12 the questions) at each of the sport venues (seven in total) over the three-day period.

\section{Data Analysis}

14 Survey data were analyzed using SPSS version 25.0 software. Chi-square tests were first

15 performed to calculate whether sociodemographic frequencies of our sample $(n=451)$ differed

16 significantly from the 2019 Youth Games athletes $(n=1,260)$. Chi-square tests were then

17 performed to calculate whether the frequencies of youth athletes across Traditional and Unified

18 sport programs and sociodemographic characteristics were significantly different across athletes

19 with $(n=402)$ versus without $(n=65)$ complete MeEAP data or athletes outside of the 12-24

20 age range $(n=34)$. A missing values analysis was then conducted to determine whether

21 experiential element item (i.e., MeEAP) data were missing at random or if there was a systematic

22 pattern related to sport program and/or sociodemographic characteristics (Pallant, 2016). 
Preliminary analyses were conducted using descriptive statistics (means, standard deviations, frequencies, skewness, and kurtosis) for each of the 12 MeEAP items. Data for all

3 MeEAP items were reflected, and then a logarithmic transformation was applied (i.e., new

4 variable $=\mathrm{LG10}[\mathrm{K}-$ old variable $]$, where $\mathrm{K}=$ largest possible value +1$)$, resulting in normally

5 distributed data (Pallant, 2016). Outliers were identified using z-scores and winsorized to the

6 next acceptable extreme case, meeting the assumptions of linearity for correlation and regression

7 analyses (Field, 2017). MeEAP data were negatively skewed (values varying from -1.97 to -

8 3.52) and exhibited high kurtosis values (varying from 3.98 to 15.45 ), and thus, were

9 transformed to meet assumptions to support use of the parametric statistical procedures.

Prior to conducting the analyses for the three research questions, Cronbach's alpha was

11 computed for the MeEAP items (Pallant, 2016). In addition, the relationships between the six

12 experiential elements of quality participation were examined using bivariate Pearson

13 correlations. The novel use of the MeEAP for measuring quality sport experiences in youth with

14 and without IDD warranted these analytical steps as an indication of the internal consistency and

15 construct validity of the MeEAP for this target group. Correlations were interpreted using

16 Cohen's (1988) guidelines, where the strength of associations was interpreted as small $(r<0.29)$,

17 moderate ( $r$ of 0.30 to 0.49$)$ or large $(r>0.50)$.

18 To compare ratings of quality participation between athletes who identified with having

19 an IDD in Traditional $(n=121)^{1}$ versus Unified $(n=86)$ Sport programs, independent $t$-tests

20 were conducted for each of the six experiential elements of the MeEAP.

21 To explore the influence of sport program and sociodemographic characteristics on youth

22 athletes' ratings of quality participation, standard multiple regression analyses were performed

\footnotetext{
${ }^{1}$ While there were 183 reported Traditional athletes, participants were only included in the independent $t$-tests if they identified with having a disability.
} 
1 separately for each of the six experiential elements using four predictor variables entered

2 simultaneously $(p<0.05$ for acceptance in the model): sport program (coded $0=$ Traditional

3 Sports; $1=$ Unified Sport), age ( $\operatorname{coded} 0=12-18$ years; $1=19+$ years), disability status (coded 0

$4=$ no disability; $1=$ reported disability), and gender $(\operatorname{coded} 0=\operatorname{girl} /$ woman; $1=$ boy $/ \mathrm{man})$.

\section{Results}

\section{Participant Sociodemographic Characteristics}

A total of 501 youth athletes participated in this study, $402(80.2 \%)$ of whom had

8 complete MeEAP data and were within the 12 to 24 age range (see Table 1). Of the 402 athletes

9 with complete MeEAP data, 272 (67.7\%) identified as a boy/man, the mean age was 17.21 years

$10 \quad(S D=2.28$; range 12-24 years), and $191(47.5 \%)$ athletes identified as having a disability. When

11 comparing our sample's sociodemographic characteristics to the 2019 Youth Games athletes,

12 significant differences emerged for age (chi-square $=224.6 ; \mathrm{df}=1 ; p=.001)$ and disability

13 status (chi-square $=102.2 ; \mathrm{df}=1 ; p=.001$ ). Our sample had a greater representation of athletes

14 who did not identify as having a disability and athletes between the ages of 12 and 17 years

15 inclusive. No significant differences were found for gender (chi-square $=.987 ; \mathrm{df}=1 ; p=.320$ ).

16 Table 1 also provides sport program and sociodemographic characteristic frequencies for

17 the 99 athletes who did not have complete MeEAP data and/or were outside of the 12 to 24 age

18 range. Chi-square test results indicated no significant differences between athletes with complete

19 MeEAP data and athletes with incomplete MeEAP data and/or outside the 12 to 24 age range.

20 Examining the Internal Consistency and Construct Validity of the MeEAP

21 Cronbach's alpha amongst the 12 MeEAP items was 0.90 , indicating good internal

22 consistency within the scale. Table 2 provides the bivariate Pearson's correlation coefficients for

23 the two corresponding MeEAP items and the overall mean experiential element scores for each 
1 of the six experiential elements of quality participation. Correlations between the two

2 corresponding MeEAP items for each experiential element were significant at $p=.01$ and varied

3 from moderate to large strength ( $r \mathrm{~s}=0.36$ to 0.54$)$. Further, the correlations for the mean

4 MeEAP element scores demonstrated moderate to large positive associations across the elements

$5 \quad(r \mathrm{~s}=0.39$ to 0.59$)$, indicating that higher scores in one experiential element were related to

6 higher scores in other experiential elements. These moderate to large positive correlations

7 between the experiential elements provide preliminary support for construct validity of the

8 MeEAP in our sample of youth with and without IDD.

9 Experiential Elements of Quality Participation

The majority of missing MeEAP values resulted from participants' preference not to

11 answer MeEAP items $(n=49)$. The remaining missing MeEAP values were due to participants

12 leaving over $50 \%$ of the responses blank $(n=8)$ or participants outside of the 12 to 24 age range

$13(n=42)^{2}$. Results indicated significance for the missing completely at random test (chi-square $=$

14 478.7; df = 269; $p=.001$; Pallant, 2016). Specifically, MeEAP item 11 (meaning item, “a sense

15 of purpose") was the only item with a pattern of $5 \%$ or more missing cases, suggesting this item

16 was not missing completely at random $(n=29,5.8 \%)$. Chi-square tests of independence for

17 MeEAP item 11 (missing values versus reported values) and the measured sport program and

18 sociodemographic characteristics showed Traditional Sports athletes were significantly more

19 likely to select the response option 'prefer not to answer' (81\%) than Unified Sport athletes

$20(19 \%), x^{2}(1, n=465)=10.94, p=.001$. No other significant differences were found for the

21 measured sociodemographic characteristics and MeEAP item 11. After reviewing the literature

22 (Tabachnick \& Fidell, 2019) and consulting with one of the MeEAP authors for advice on how

\footnotetext{
${ }^{2}$ Participants outside of the 12 to 24 age range were included in the preliminary analysis to provide the reader with a greater understanding of the sample characteristics for those included compared to those excluded in this study.
} 
1 to proceed in the case of missing MeEAP responses, we decided to include the 49 participants

2 who had completed $>67 \%$ of the MeEAP survey using mean-replacement. Specifically, the

3 mean for the MeEAP item that corresponded to the missing value was inputted. The remaining

450 participants were excluded from the analyses as they were outside of the 12 to 24 age range $(n$

$5=42)$ or had $>50 \%$ of MeEAP data incomplete $(n=8)$.

6 Table 3 displays the descriptive statistics for the sample of 451 youth athletes included in

7 the final analyses (mean age $=17.20$ years, $S D=2.29$ ), according to sport program and

8 sociodemographic characteristics. MeEAP item scores from the youth across the subgroups of

9 age, disability status, gender, and sport program indicated high quality sport participation for all

10 six experiential elements (means varied from 6.19 to 6.51 out of a possible score of 7).

\section{Experiential Elements for Athletes with IDD Across Sport Program}

12 Results from the independent $t$-tests comparing each of the six experiential elements

13 across athletes with IDD in Traditional versus Unified sport programs revealed no significant

14 differences ( $t$ values of -0.15 to 0.25 , all $p$ values $>0.15$ ). These findings indicate that the mean

15 scores for each of the six experiential elements were similar across Traditional and Unified Sport

16 for athletes with IDD. See Table 3 for the experiential mean scores across sport program.

17 Sport Program and Sociodemographic Characteristics as Predictors of Experiential

18 Elements

19 Table 4 summarizes the results from the multiple regression analyses for each of the six

20 experiential elements, using sport program, age, gender, and disability status as predictors.

21 Disability status $\left(F=2.06, R^{2}=0.02, b=0.02, p=0.01\right)$ was significantly predictive of

22 autonomy, such that athletes who did not identify as having a disability reported higher

23 autonomy scores for their Special Olympics sport programs than athletes who identified as 
1 having a disability. There were no other significant sociodemographic and sport program

2 predictors for the experiential elements. However, there was an indication of a pattern of

3 association for gender $\left(F=1.91, R^{2}=0.02, b=0.03, p=0.07\right)$, suggesting women reported

4 higher engagement in their Special Olympics sport programs than men.

\section{Discussion}

This is the first study to investigate experiential elements of quality participation in sport among youth athletes with and without IDD. Findings indicate that youth athletes with and without IDD perceived their Special Olympics sport programming, regardless of sport program

9 type, to facilitate quality sport experiences, as shown by high mean scores across all six 10 experiential elements (means ranged from 6.27 to 6.40 out of 7). In addition to high mean scores

11 of quality participation for athletes with IDD, there were no significant differences related to

12 participating in Traditional Sport compared to Unified Sport, suggesting that both programs may

13 strongly support the sport participation of athletes with IDD. Moreover, sport program type was

14 not a significant predictor for any of the six experiential elements. Accordingly, this study

15 supports previous literature which found that sport participation for youth with IDD, and Special

16 Olympics programming in particular, can provide enjoyable and meaningful outcomes such as

17 increased self-worth, positive emotions, friendships, and motor skills (e.g., Tint et al., 2017).

18 While not part of this study's primary focus, our findings also demonstrate that the six

19 experiential elements of quality participation are significantly and positively correlated with each

20 other, such that a high rating of one experiential element relates to a high rating in each of the

21 five other experiential elements. Theoretically, this demonstrates relatedness between the

22 experiential elements of quality participation and extends the applicability of Evans et al.'s

23 (2018) quality parasport participation framework to youth athletes with and without IDD. 


\section{Sport Program and Experiential Elements of Quality Participation}

Contrary to previous evidence regarding Special Olympics participation experiences, the

3 sport program itself neither predicted the quality of participation nor were there differences in the

4 quality of participation when comparing athletes with IDD in Traditional Sports and athletes

5 with IDD in Unified Sport. Importantly, Unified Sport may promote the same high-quality sport

6 experiences as Traditional (i.e., segregated) Sports programs. Prior studies examining

7 participation experiences within Traditional and integrated sport environments highlighted the

8 need for integrated sport staff to monitor noticeable gaps in skill level across athletes with and

9 without IDD to ensure all youth were optimally supported (Goodwin et al., 2006; Ninot et al.,

10 2005; Ninot \& Maïano, 2007). Although experiencing success in sport was a recognized priority

11 among athletes, parents of youth with IDD described feelings of discomfort as a result of poorly

12 equipped instructors and subsequently, inadequately tailored integrated sport environments

13 (Goodwin et al., 2006). It is important to acknowledge that these previous studies examined

14 Special Olympics Traditional Sports but lacked direct comparison to Unified Sport programs.

15 Our concurrent examination of Traditional Sports and Unified Sport programming may explain

16 why quality experience scores were consistently high across both groups, resulting in no

17 significant differences in the experiential elements. Our findings speak to the value of Traditional

18 Sport and offer evidence to support that quality experiences are consistent within the new

19 Unified Sport program. Furthermore, these findings may mitigate parents' reported hesitancy to

20 enroll their youth with IDD in Unified Sport programs (Goodwin et al., 2006).

\section{Sociodemographic Characteristics as Predictors of Experiential Elements of Quality}

\section{Participation}


When analyzing sociodemographic characteristics for all six experiential elements of quality participation, there were two patterns that emerged. The first was that disability status

3 was a significant predictor of autonomy, such that those athletes who did not identify as having a

4 disability reported higher ratings of autonomy compared to those who identified with having a 5 disability. Autonomy-supportive participation environments for youth with IDD is a crucial, yet

6 understudied, area of research (Deci, 2004; Orr et al., 2019). Studies investigating factors

7 positively impacting community participation among persons with IDD noted the importance of

8 integrating opportunities to make choices (Farrell et al., 2004; Verdonschot et al., 2009) and

9 ensuring that persons with IDD experience social support, positive staff attitudes (Verdonschot et

10 al., 2009), friendships, and a sense of achievement (Darcy \& Dowse, 2013; Harada \& Siperstein,

11 2009) within sporting environments. Given the high prevalence of social isolation and the low

12 sport participation levels among youth with IDD (Akrami et al., 2006; McConkey et al., 2013),

13 disability sport organizations may prefer to focus their efforts on fostering social acceptance

14 through a sense of community (e.g., belongingness) and skill development through appropriately

15 adapted environments (e.g., mastery and challenge) to promote long-term sport involvement.

16 The second pattern, though not significant, was that gender may predict engagement,

17 such that women reported higher perceived engagement in their Special Olympics sports

18 programs than men. Within the disability sport literature, women participate less in sport

19 programs compared to men, and the women who do participate demonstrate high dropout rates

20 (Goodwin et al., 2006). As such, ensuring that women have access to participation environments

21 that promote and support quality experiences is imperative to mitigating the concerning

22 discrepancies in sport involvement. Interestingly, our study results suggest that once women do

23 enter the sport environment, Special Olympics programs are able to provide quality sport 
1 experiences for them, as demonstrated by the high ratings by girls/women across all six

2 experiential elements of quality participation. Moreover, the pattern that women reported greater

3 engagement compared to men is promising for maintained sport participation and, subsequently,

4 reduced dropout rates. Future research should investigate the environmental strategies that enable

5 women to feel fully engaged in Special Olympics sport programs. Once these strategies are

6 better understood, other sport initiatives designed for youth with and without IDD may be able to

7 more effectively facilitate and support quality participation for all athletes, especially women.

8 Consistent with Evans et al.'s (2018) recommendations to focus on one or more of the

9 experiential elements to satisfy athlete needs, Special Olympics may have prioritized experiential

10 elements that aligned with the organization's values (i.e., belongingness, mastery, and challenge)

11 to promote sport environments that foster inclusion and respect, facilitate fair and safe

12 competition, and enhance sport skills (Robinson et al., 2018; Weiss et al., 2017). The moderate

13 to strong associations among the six experiential elements suggest that if sport program

14 providers do not have the capacity to focus on all six experiential elements, they may be able to

15 focus on one element, while simultaneously and indirectly influencing the others. For example,

16 program providers may prioritize challenge (e.g., appropriately testing an athlete) within

17 sessions, which may foster mastery (e.g., feeling competent) when athletes are appropriately

18 pushed beyond their comfort zone. Thus, program providers might be advised to focus their

19 efforts on effectively integrating one or some experiential elements, rather than attempting to

20 incorporate all six experiential elements poorly.

21 When conducting further investigations into the experiences of youth athletes with IDD

22 in Special Olympics programming, we found no significant differences across experiential

23 elements between athletes with IDD in Traditional Sports compared to Unified Sport. The high 
1 ratings of all six experiential elements of quality participation among youth athletes with and

2 without IDD strongly suggest that Special Olympics programming offers quality sport

3 experiences. Nonetheless, Special Olympics may be able to further enhance programming by

4 focusing future efforts on strategies that promote autonomy and engagement for youth athletes.

\section{Strengths and Limitations}

$6 \quad$ Our study explored quality participation experiences within Special Olympics sport

7 programming using self-report measures, thereby mitigating the proxy reporting concerns

8 common in research involving youth with IDD (Glidden et al., 2011; Holburn et al., 2007; Tint et

9 al., 2017). A total of 501 participants with and without IDD participated in this study accounting

10 for approximately 40\% of all athletes involved in the 2019 Special Olympics Youth Games.

11 Youth athletes were recruited across all five sports at the Youth Games (i.e., athletics, basketball,

12 bocce, floor hockey, and soccer) at seven sporting event locations. Data collection was

13 accomplished despite the limited time offered between tournament games to interact with the

14 athletes. Notably, our findings extend understandings of quality participation for youth with and

15 without IDD, and offer important theoretical and practical insights that can help to ensure all

16 athletes are optimally supported in their participation in different sport environments.

17 Our sample had a significantly greater representation of athletes without IDD and athletes

18 between the ages of 12-17 compared to the 2019 Youth Games athletes. As such, although our

19 team recruited around $40 \%$ of Youth Games attendees, our results may not be as generalizable as

20 anticipated. While engaging with youth with IDD, challenges were experienced during

21 measurement of the experiential elements of quality participation. The preliminary analyses

22 presented a significant pattern in the missing value analysis for MeEAP item 11, which is

23 associated with the experiential element of 'meaning' (i.e., a sense of purpose). Accordingly, 
1 future investigations should consider why youth preferred not to answer this item and explore

2 other ways to measure an abstract concept like 'meaning' for persons with IDD.

Additionally, athletes may not have understood all of the MeEAP items, and this was

4 perhaps exacerbated by the study's self-report survey design in which help was provided only as

5 requested. For example, when our research team assisted participants by verbally reading survey

6 questions, we perceived participant difficulties in understanding the wording of MeEAP item 7

7 "entirely focused on what I am doing" associated with the engagement element. Specifically,

8 assessing focus during sport may not accurately reflect whether they are adequately engaged.

9 Given that intellectual disability is characterized by limitations in intellectual functioning and

10 adaptive behaviour (i.e., conceptual, social, and practical skills; American Association on

11 Intellectual and Developmental Disabilities, 2020), it may be harder to grasp what engagement -

12 in the moment, flow - means to youth with IDD. Thus, although the six experiential elements of

13 quality participation demonstrate applicability to youth athletes with and without IDD, the

14 meaning and engagement items of the MeEAP may need to be modified to increase accessibility

15 of wording to better capture the first-hand experiences of youth with IDD. Given that the

16 MeEAP is validated for adults with physical disabilities, we recognize the limitation of using it

17 for youth athletes with and without IDD. While our investigation offers preliminary support use

18 of this measure of quality participation among youth athletes with and without IDD, future

19 research is needed to provide a deeper understanding of the psychometric properties (i.e., test-

20 retest reliability and construct validity) of the MeEAP when used with youth.

\section{Future Directions}

22 To understand how Special Olympics sport programs elicit high ratings for all

23 experiential elements of quality participation across sport program and sociodemographic 
1 characteristics, future research should track experiential elements ratings over time while

2 exploring the nuances of sport experience using mixed methods. Our study investigated the

3 importance of the six experiential elements of quality participation in sport environments for

4 Special Olympics athletes to explore whether programming can offer quality participation for

5 youth with and without IDD. However, as Evans et al. (2018) proposed, foundational strategies -

6 conditions such as rules, facilities, normative beliefs, and policies that impact element facilitation

7 - should be considered as a part of the bigger picture of quality participation for youth. Thus, we

8 recommend that subsequent studies prioritize how Special Olympics athletes experience the six

9 experiential elements to further enhance the design, implementation, and evaluation of these

10 participation environments and similar disability sport initiatives for youth with IDD.

\section{Conclusions}

Overall, this study provides promising findings concerning quality sport participation

13 experiences for youth athletes with and without IDD participating in Special Olympics'

14 Traditional and Unified Sport programs. Athletes reported high mean scores for all six

15 experiential elements of participation (i.e., autonomy, belongingness, challenge, engagement,

16 mastery, and meaning), regardless of age, disability status, gender, or sport program (i.e.,

17 Traditional Sport and Unified Sport). Athletes who did not identify with having a disability were

18 more likely to report higher feelings of autonomy in sport than those who reported a disability.

19 Women were more likely to report higher feelings of engagement in sport than men, although,

20 this pattern was not significant. Apart from these differences, the six experiential elements were

21 not significantly predicted by age, disability status, gender, or sport program. From a practical

22 application standpoint, our investigation provides sport coaches and instructors with greater

23 knowledge and understanding of how to enhance their programs for all youth. 
QUALITY PARTICIPATION IN SPECIAL OLYMPICS

\section{References}

2 Akrami, N., Ekehammar, B., Claesson, M., \& Sonnander, K. (2006). Classical and modern

3 prejudice: Attitudes towards people with intellectual disabilities. Research in Developmental

4 Disabilities, 27(6), 605-617. https://doi.org/10.1016/j.ridd.2005.07.003

5 Allan, V., Smith, B., Côté, J., Martin Ginis, K. A., \& Latimer-Cheung, A. E. (2018). Narratives

6 of participation among individuals with physical disabilities: A life-course analysis of

7 athletes' experiences and development in parasport. Psychology of Sport and Exercise, 37,

8 170-178. http://dx.doi.org/10.1016/j.psychsport.2017.10.004.

9 American Association on Intellectual and Developmental Disabilities. (2020, October 21).

10 Frequently asked questions on intellectual disability. https://www.aaidd.org/intellectual-

11 disability/definition/faqs-on-intellectual-disability

12 Caron, J. G., Martin Ginis, K. A., Rocchi, M., \& Sweet, S. N. (201). Development of the

13 measure of experiential aspects of participation for people with physical disabilities. Archives

14 of Physical Medicine and Rehabilitation, 100 (1), 67-77.

15 https://doi.org/10.1016/j.apmr.2018.08.183

16 Cohen, J. (1988). Statistical power analysis for the behavioral sciences. Hillsdale, NJ: Erlbaum.

17 https://doi.org/10.4324/9780203771587

18 Crawford, C., Burns, J., \& Fernie, B. (2015). Psychosocial impact of involvement in the special

19 olympics. Research in Developmental Disabilities, 45-46, 93-102.

20 doi:10.1016/j.ridd.2015.07.009.

21 Darcy, S., \& Dowse, L. (2013). In search of a level playing field-The constraints and benefits of

22 sport participation for people with intellectual disability. Disability \& Society, 28(3), 393-

23 407. https://doi.org/10.1080/09687599.2012.714258 
QUALITY PARTICIPATION IN SPECIAL OLYMPICS

1 Deci, E. L. (2004). Promoting intrinsic motivation and self-determination in people with mental retardation. International Review of Research in Mental Retardation Personality and Motivational Systems in Mental Retardation, 28, 1-29. https://doi.org/10.1016/S0074$7750(04) 28001-6$

5

Eime, R. M., Young, J. A., Harvey, J. T., Charity, M. J., \& Payne, W. R. (2013). A systematic review of the psychological and social benefits of participation in sport for children and adolescents: informing development of a conceptual model of health through sport. International Journal of Behavioral Nutrition and Physical Activity, 10(1), 98-119. https://doi.org/10/1186/1479-5868-10-98

Evans, M. B., Shirazipour, C. H., Allan, V., Zanhour, M., Sweet, S. N., Martin Ginis, K. A., \& Latimer-Cheung, A. E. (2018). Integrating insights from the parasport community to understand optimal experiences: the quality parasport participation framework. Psychology of Sport and Exercise, 37, 79-90. https://doi.org/10.1016/j.psychsport.2018.04.009

Farrell, R. J., Crocker, P. R. E., McDonough, M. H., \& Sedgwick, W. A. (2004). The driving force: Motivation in Special Olympians. Adapted Physical Activity Quarterly, 21, 153-168. https://doi.org/10.1123/apaq.21.2.153

Field, A. (2017). Discovering Statistics Using IBM SPSS Statistics. (5th ed.). Sage Publications.

Gillespie, M. (2009). Participation patterns in an urban Special Olympics programme. British Journal of Learning Disabilities, 37(1), 21-27. https://doi.org/10.1111/j.14683156.2008.00496.x

Glidden, L. M., Bamberger, K. T., Draheim, A. R., \& Kersh, J. (2011). Parent and athlete perceptions of Special Olympics participation: utility and danger of proxy responding. 
QUALITY PARTICIPATION IN SPECIAL OLYMPICS

Intellectual and Developmental Disabilities, 49(1), 37-45. https://doi.org/10.1352/1934$9556-49.1 .37$

3 Goodwin, D. L., Fitzpatrick, D. A., Thurmeier, R., \& Hall, C. (2006). The decision to join

4 Special Olympics: parents’ perspectives. Adapted Physical Activity Quarterly, 23(2), $163-$

5 183. https://doi.org/10.1123/apaq.23.2.163

6 Gough, D., Thomas, J., \& Oliver, S. (2012). Clarifying differences between review designs and

7 methods. Systematic Reviews, 1(1), 28-37. https://doi.org/10.1186/2046-4053-1-28

8 Harris, P. A., Taylor, R., Thielke, R., Payne, J., Gonzalez, N., \& Conde, J. G. (2009). Research

9 electronic data capture (REDCap) - A metadata-driven methodology and workflow process

10 for providing translational research informatics support. Journal of Biomedical Informatics,

11 42(2), 377-381. https://doi.org/10.1016/j.jbi.2008.08.010

12 Hassan, D., Dowling, S., McConkey, R., \& Menke, S. (2012). The inclusion of people with

13 intellectual disabilities in team sports: lessons from the Youth Unified Sports programme of

14 Special Olympics. Sport in Society, 15(9), 1275-1290.

15 https://doi.org/10.1080/17430437.2012.695348

16 Holburn, S., Cea, C. D., Coull, L., \& Goode, D. (2007). Personal vs. proxy focus groups'

17 perspectives on quality of life. Journal of Policy and Practice in Intellectual Disabilities,

18 4(3), 210-212. https://doi.org/10.1111/j.1741-1130.2007.00120.x

19 Martin Ginis, K. A., Evans, B., Mortenson, B., \& Noreau, L. (2017). Broadening the

20 conceptualization of participation of persons with physical disabilities: A configurative

21 review and recommendations. Archives of Physical Medicine and Rehabilitation, 98(2), 395-

22 402. https://doi.org/10.1016/j.apmr.2016.04.017 
1 McConkey, R., Dowling, S., Hassan, D., \& Menke, S. (2013). Promoting social inclusion

2 through Unified Sports for youth with intellectual disabilities: a five-nation study. Journal of

3 Intellectual Disability Research, 57(10), 923-935. https://doi.org/10.1111/j.1365-

$4 \quad 2788.2012 .01587 . x$

5 McGarty, A. M., \& Melville, C. A. (2018). Parental perceptions of facilitators and barriers to

6 physical activity for children with intellectual disabilities: A mixed methods systematic

7 review. Research in Developmental Disabilities, 73, 40-57.

8 https://doi.org/10.1016/j.ridd.2017.12.007

9 Montesano, P. (2014). Improvement of the coordination skills in disabled athletes Special

10 Olympics. Journal of Physical Education and Sport, 14, 301-305.

11 https://doi.org/10.7752/jpes.2014.02045

12 Ninot, G., Bilard, J., \& Delignieres, D. (2005). Effects of integrated or segregated sport

13 participation on the physical self for adolescents with intellectual disabilities. Journal of

14 Intellectual Disability Research, 49(9), 682-689. https://doi.org/10.1111/j.1365-

$15 \quad 2788.2005 .00407 . x$

16 Ninot, G., \& Maïano, C. (2007). Long-term effects of athletics meet on the perceived

17 competence of individuals with intellectual disabilities. Research in Developmental

18 Disabilities, 28(2), 176-186. https://doi.org/10.1016/j.ridd.2006.02.008

19 Oliveira, A., Monteiro, Â., Jácome, C., Afreixo, V., \& Marques, A. (2017). Effects of group

20 sports on health-related physical fitness of overweight youth: A systematic review and meta-

21 analysis. Scandinavian Journal of Medicine \& Science in Sports, 27(6), 604-611.

22 https://doi.org/10.1111/sms.12784 
1 Orr, K., Evans, M. B., Tamminen, K. A., \& Arbour-Nicitopoulos, K. P. (2019). A scoping

2 review of recreational sport programs for disabled emerging adults. Research Quarterly for

3 Exercise and Sport, 91(1), 1-16. https://doi.org/10.1080/02701367.2019.1653432

4 Pallant, J. (2016). SPSS Survival Manual: A step by step guide to data analysis using IBM SPSS.

$5 \quad\left(6^{\text {th }}\right.$ ed. $)$. Open University Press.

6 Reinders, N. J., Branco, A., Wright, K., Fletcher, P. C., \& Bryden, P. J. (2019). Scoping review:

$7 \quad$ Physical activity and social functioning in young people with autism spectrum disorder.

8 Frontiers in Psychology, 10, 120-137. https://doi.org/10.3389/fpsyg.2019.00120

9 Robinson, F., Fraser-Thomas, J. L., Balogh, R., Lunsky, Y., \& Weiss, J. A. (2018). Individual

10 and contextual correlates of frequently involved Special Olympics athletes. American Journal

11 on Intellectual and Developmental Disabilities, 123(2), 164-175.

12 https://doi.org/10.1352/1944-7558-123.2.164

13 Shapiro, D. (2003). Participation motives of Special Olympics athletes. Adapted Physical

14 Activity Quarterly, 20(2), 150-165. https://doi.org/10.1123/apaq.20.2.150

15 Shields, N., \& Synnot, A. (2016). Perceived barriers and facilitators to participation in physical

16 activity for children with disability: A qualitative study. BMC Pediatrics, 16(1), 9-9.

17 https://doi.org/10.1186/s12887-016-0544-7

18 Shirazipour, C. H., Evans, M. B., Caddick, N., Smith, B., Aiken, A. B., Martin Ginis, K. A., \&

19 Latimer-Cheung, A. E. (2017). Quality participation experiences in the physical activity

20 domain: Perspectives of veterans with a physical disability. Psychology of Sport and

21 Exercise, 29, 40-50. http://dx.doi.org/10.1016/j.psychsport.2016.11.007.

22 Tabachnick B. G., \& Fidell L. S. (2019). Chapter 4: Cleaning up your act - Screening data prior

23 to analysis. In Using Multivariate Statistics ( $7^{\text {th }}$ ed., pp. 52-97). Pearson. 
QUALITY PARTICIPATION IN SPECIAL OLYMPICS https://www.pearson.com/us/higher-education/program/Tabachnick-Using-MultivariateStatistics-7th-Edition/PGM2458367.html?tab=overview

3 Tint, A., Thomson, K., \& Weiss, J. (2017). A systematic literature review of the physical and

4 psychosocial correlates of Special Olympics participation among individuals with intellectual

5 disability. Journal of Intellectual Disability Research, 61(4), 301-324.

6 https://doi.org/10.1111/jir.12295

7 United Nations. (2013, January 23rd). Definition of Youth.

8 https://www.un.org/esa/socdev/documents/youth/fact-sheets/youth-definition.pdf

9 Verdonschot, M. M., Witte, L. P., Reichrath, E., Buntinx, W. H., \& Curfs, L. M. (2009). Impact

10 of environmental factors on community participation of persons with an intellectual

11 disability: A systematic review. Journal of Intellectual Disability Research, 53(1), 54-64.

12 https://doi.org/10.1111/j.1365-2788.2008.01128.x

13 Weiss, J. A., Riosa, P. B., Robinson, S., Ryan, S., Tint, A., Viecili, M., MacMullin, J. A., \&

14 Shine, R. (2017). Understanding Special Olympics experiences from the athlete perspectives

15 using photo-elicitation: A qualitative study. Journal of Applied Research in Intellectual

16 Disabilities, 30(5), 936-945. https://doi.org/10.1111/jar.12287

17 Wilson, N. J., Jaques, H., Johnson, A., \& Brotherton, M. L. (2016). From social exclusion to

18 supported inclusion: Adults with intellectual disability discuss their lived experiences of a

19 structured social group. Journal of Applied Research in Intellectual Disabilities, 30(5), 847-

20 858. https://doi.org/10.1111/jar.12275 


\section{Table 1}

Frequencies of Sport Program and Sociodemographic Characteristics for Athletes with Complete Data and Athletes with Incomplete Data.

\begin{tabular}{|c|c|c|}
\hline Variable & $\begin{array}{l}\text { Athletes with complete } \\
\text { MeEAP data } \\
n=402\end{array}$ & $\begin{array}{c}\text { Athletes with incomplete } \\
\text { MeEAP data and/or Outside } \\
\text { the } 12-24 \text { age range } \\
n=99\end{array}$ \\
\hline \multicolumn{3}{|l|}{ Sport Program } \\
\hline Unified & $222(55.2 \%)$ & $30(30.3 \%)$ \\
\hline Traditional & $158(39.3 \%)$ & $55(55.6 \%)$ \\
\hline Prefer not to answer & $22(5.5 \%)$ & $11(11.1 \%)$ \\
\hline Not Reported & -- & $3(3.0 \%)$ \\
\hline \multicolumn{3}{|l|}{ Sociodemographic } \\
\hline \multicolumn{3}{|l|}{ Characteristics } \\
\hline \multicolumn{3}{|l|}{ Age } \\
\hline $0-12$ years & -- & $2(2.0 \%)$ \\
\hline $12-18$ years & $291(72.4 \%)$ & $42(42.4 \%)$ \\
\hline $19-24$ years & $111(27.6 \%)$ & $15(15.2 \%)$ \\
\hline $25+$ years & -- & $32(32.3 \%)$ \\
\hline Not Reported & -- & $8(8.1 \%)$ \\
\hline \multicolumn{3}{|l|}{ Disability Status } \\
\hline Yes & $191(47.5 \%)$ & $48(48.5 \%)$ \\
\hline No & $157(39.1 \%)$ & $23(23.2 \%)$ \\
\hline Prefer not to answer & $54(13.4 \%)$ & $25(25.3 \%)$ \\
\hline Not Reported & -- & $3(3.0 \%)$ \\
\hline \multicolumn{3}{|l|}{ Gender } \\
\hline Boy/Man & $272(67.7 \%)$ & $69(69.7 \%)$ \\
\hline Girl/Woman & $130(32.3 \%)$ & $26(26.3 \%)$ \\
\hline Other Gender & -- & $1(1.0 \%)$ \\
\hline Not Reported & -- & $3(3.0 \%)$ \\
\hline
\end{tabular}

Note. Chi-square test results indicate no significant differences between athletes with complete MeEAP data and athletes with incomplete MeEAP data and/or outside the 12-24 age range. 


\section{Table 2}

Bivariate Pearson Correlations for Experiential Elements of Quality Participation.

\begin{tabular}{lcccccc} 
Element (Item-Correlation) & 1 & 2 & 3 & 4 & 5 & 6 \\
\hline 1. Autonomy (.36) & - & $0.53^{* *}$ & $0.46^{* *}$ & $0.55^{* *}$ & $0.49^{* *}$ & $0.39^{* *}$ \\
2. Belongingness $(.54)$ & $0.53^{* *}$ & - & $0.49^{* *}$ & $0.59^{* *}$ & $0.48^{* *}$ & $0.51^{* *}$ \\
3. Challenge (.36) & $0.46^{* *}$ & $0.49^{* *}$ & - & $0.45^{* *}$ & $0.52^{* *}$ & $0.49^{* *}$ \\
4. Engagement $(.49)$ & $0.55^{* *}$ & $0.59^{* *}$ & $0.45^{* *}$ & - & $0.52^{* *}$ & $0.57^{* *}$ \\
5. Mastery $(.36)$ & $0.49^{* *}$ & $0.48^{* *}$ & $0.52^{* *}$ & $0.52^{* *}$ & - & $0.47^{* *}$ \\
6. Meaning (.45) & $0.39^{* *}$ & $0.51^{* *}$ & $0.49^{* *}$ & $0.57^{* *}$ & $0.47^{* *}$ & - \\
Mean & 6.32 & 6.34 & 6.25 & 6.38 & 6.29 & 6.26 \\
Standard Deviation & 0.96 & 1.04 & 1.04 & 0.97 & 1.02 & 1.03
\end{tabular}

Note. Item-correlation refers to the bivariate Pearson correlation coefficient for the two corresponding experiential element items from the MeEAP (e.g., autonomy item 1 "that I do what is good for me," and autonomy item 2 "free to make my own choices").

** Significant correlations at the $p<.01$ level, two-tailed. 


\section{Table 3}

Descriptives Statistics of Experiential Elements of Quality Participation According to Sport Program and Sociodemographic Characteristics $(n=451)$.

\begin{tabular}{|c|c|c|c|c|c|c|c|}
\hline Variable & $n$ & $\begin{array}{l}\text { Autonomy } \\
\text { Mean (SD) }\end{array}$ & $\begin{array}{c}\text { Belongingness } \\
\text { Mean (SD) }\end{array}$ & $\begin{array}{l}\text { Challenge } \\
\text { Mean (SD) }\end{array}$ & $\begin{array}{l}\text { Engagement } \\
\text { Mean (SD) }\end{array}$ & $\begin{array}{c}\text { Mastery } \\
\text { Mean (SD) }\end{array}$ & $\begin{array}{c}\text { Meaning } \\
\text { Mean (SD) }\end{array}$ \\
\hline \multicolumn{8}{|l|}{ Sport Program } \\
\hline Unified (all athletes) $)^{\mathrm{a}}$ & 237 & $6.42(0.97)$ & $6.37(1.04)$ & $6.30(1.07)$ & $6.46(1.00)$ & $6.29(1.09)$ & $6.26(1.07)$ \\
\hline Unified (athletes with IDD) ${ }^{\mathrm{b}}$ & 86 & $6.26(1.10)$ & $6.18(1.13)$ & $6.07(1.26)$ & $6.24(1.21)$ & $6.12(1.27)$ & $6.17(1.22)$ \\
\hline Traditional & 183 & $6.23(0.87)$ & $6.34(0.99)$ & $6.23(0.98)$ & $6.34(0.87)$ & $6.34(0.87)$ & $6.27(0.96)$ \\
\hline \multicolumn{8}{|l|}{ Sociodemographic Characteristics } \\
\hline \multicolumn{8}{|l|}{ Age } \\
\hline $12-18$ years & 327 & $6.30(0.96)$ & $6.31(1.07)$ & $6.26(1.07)$ & $6.36(0.98)$ & $6.25(1.06)$ & $6.23(1.05)$ \\
\hline $19-24$ years & 124 & $6.37(0.94)$ & $6.42(0.95)$ & $6.22(0.95)$ & $6.45(0.94)$ & $6.39(0.90)$ & $6.33(0.96)$ \\
\hline \multicolumn{8}{|l|}{ Disability Status } \\
\hline Yes & 212 & $6.25(1.04)$ & $6.27(1.09)$ & $6.19(1.11)$ & $6.27(1.06)$ & $6.25(1.09)$ & $6.21(1.09)$ \\
\hline No & 170 & $6.44(0.89)$ & $6.41(1.01)$ & $6.31(0.97)$ & $6.51(0.91)$ & $6.36(0.96)$ & $6.25(1.04)$ \\
\hline \multicolumn{8}{|l|}{ Gender } \\
\hline Boy/Man & 306 & $6.30(0.93)$ & $6.30(1.06)$ & $6.24(1.01)$ & $6.33(0.97)$ & $6.26(1.01)$ & $6.25(0.97)$ \\
\hline Girl/Woman & 145 & $6.34(1.01)$ & $6.42(1.00)$ & $6.27(1.11)$ & $6.49(0.97)$ & $6.35(1.02)$ & $6.28(1.14)$ \\
\hline
\end{tabular}

Note. Experiential elements responses were reported on a 7-point Likert scale (1 [strongly disagree] to 7 [strongly agree]). Data displayed represents untransformed quality experiential element scores for ease of interpretation. Of the 451 participants included in the analyses, 402 had complete MeEAP data. The remaining 49 had completed $>67 \%$ of the MeEAP survey and were included in our analyses using mean-replacement. Specifically, the mean for the MeEAP item that corresponds to the missing value was inputted. ${ }^{a}$ Mean values for the six experiential elements are shown for the sample of athletes with $(n=86)$ and without $(n=151)$ IDD who reported participating in Unified Sport.

${ }^{b}$ Mean values for the six experiential elements are shown for the subsample of athletes with IDD $(n=86)$ who reported participating in Unified Sport. 


\section{Table 4}

Multiple Regression Analysis of Experiential Elements of Quality Participation According to Sport Program and Sociodemographic Characteristics.

\begin{tabular}{|c|c|c|c|c|c|}
\hline $\begin{array}{l}\text { Element of } \\
\text { Quality } \\
\text { Participation }\end{array}$ & $\begin{array}{c}\text { Sport Program and } \\
\text { Sociodemographic } \\
\text { Characteristics }\end{array}$ & $B(\mathrm{SE})$ & $95 \% \mathrm{CI}$ & $\begin{array}{c}\text { Standardized } \\
\text { Coefficients } \\
\text { Beta } \\
\end{array}$ & $p$-value \\
\hline \multirow[t]{4}{*}{ Autonomy } & Sport Program & $-.006(.011)$ & $-.028, .016$ & -.025 & .592 \\
\hline & Age & $-.025(.020)$ & $-.028, .016$ & -.059 & .211 \\
\hline & Disability Status* & .023 (.009) & $.006, .041$ & .122 & .010 \\
\hline & Gender & $.008(.017)$ & $-.026, .042$ & .022 & .633 \\
\hline \multirow[t]{4}{*}{ Belongingness } & Sport Program & $.010(.012)$ & $-.014, .033$ & .037 & .432 \\
\hline & Age & $-.025(.021)$ & $-.067, .017$ & -.056 & .242 \\
\hline & Disability Status & $.009(.010)$ & $-.009, .028$ & .046 & .326 \\
\hline & Gender & $.024(.019)$ & $-.013, .060$ & .061 & .199 \\
\hline \multirow[t]{4}{*}{ Challenge } & Sport Program & $.005(.012)$ & $-.019, .028$ & .018 & .703 \\
\hline & Age & $.018(.021)$ & $-.023, .060$ & .042 & .384 \\
\hline & Disability Status & $.001(.009)$ & $-.017, .020$ & .005 & .914 \\
\hline & Gender & $.012(.018)$ & $-.024, .048$ & .032 & .496 \\
\hline \multirow[t]{4}{*}{ Engagement } & Sport Program & $.003(.011)$ & $-.020, .025$ & .011 & .817 \\
\hline & Age & $-.026(.020)$ & $-.065, .013$ & -.061 & .196 \\
\hline & Disability Status & $.015(.009)$ & $-.002, .033$ & .082 & .084 \\
\hline & Gender & $.031(.017)$ & $-.003, .065$ & .085 & .070 \\
\hline \multirow[t]{4}{*}{ Mastery } & Sport Program & $.013(.012)$ & $-.011, .036$ & .050 & .291 \\
\hline & Age & $-.028(.021)$ & $-.069, .013$ & -.063 & .186 \\
\hline & Disability Status & $.014(.009)$ & $-.004, .033$ & .071 & .134 \\
\hline & Gender & $.024(.018)$ & $-.012, .059$ & .061 & .197 \\
\hline \multirow[t]{4}{*}{ Meaning } & Sport Program & $.001(.012)$ & $-.023, .024$ & .003 & .943 \\
\hline & Age & $-.019(.021)$ & $-.060, .022$ & -.044 & .359 \\
\hline & Disability Status & $-.010(.009)$ & $-.028, .009$ & -.049 & .300 \\
\hline & Gender & $.019(.018)$ & $-.017, .054$ & .048 & .311 \\
\hline
\end{tabular}

$\mathrm{B}=$ Unstandardized coefficient; $\mathrm{SE}=$ Standard Error; Statistically significant associations $(p<$ $.05)$ are bolded with an asterisk $(*)$. 